Review

\title{
Nanotribological Behavior of Carbon Based Thin Films: Friction and Lubricity Mechanisms at the Nanoscale
}

\section{Costas A. Charitidis *, Elias P. Koumoulos and Dimitrios A. Dragatogiannis}

Department of Chemical Engineering 9 Heroon, National Technical University of Athens, Polytechneiou Street, Zografos, Athens GR-15780, Greece; E-Mails: elikoum@chemeng.ntua.gr (E.P.K.); dragatogiannis@hotmail.com (D.A.D.)

* Author to whom correspondence should be addressed; E-Mail: charitidis@chemeng.ntua.gr; Tel.: +30-2107-724-046; Fax: +30-2107-722-339.

Received: 31 December 2012; in revised form: 28 January 2013 / Accepted: 1 March 2013 / Published: 2 April 2013

\begin{abstract}
The use of materials with very attractive friction and wear properties has raised much attention in research and industrial sectors. A wide range of tribological applications, including rolling and sliding bearings, machining, mechanical seals, biomedical implants and microelectromechanical systems (MEMS), require thin films with high mechanical strength, chemical inertness, broad optical transparency, high refractive index, wide bandgap excellent thermal conductivity and extremely low thermal expansion. Carbon based thin films like diamond, diamond-like carbon, carbon nitride and cubic boron nitride known as "super-hard" material have been studied thoroughly as the ideal candidate for tribological applications. In this study, the results of experimental and simulation works on the nanotribological behavior of carbon films and fundamental mechanisms of friction and lubricity at the nano-scale are reviewed. The study is focused on the nanomechanical properties and analysis of the nanoscratching processes at low loads to obtain quantitative analysis, the comparison obtain quantitative analysis, the comparison of their elastic/plastic deformation response, and nanotribological behavior of the a-C, ta-C, a-C:H, $\mathrm{CN}_{x}$, and a-C:M films. For ta-C and a-C:M films new data are presented and discussed.
\end{abstract}

Keywords: amorphous carbon films; nanocomposites; nanoindentation; friction; nanotribology; lubricity; wear; molecular dynamics 


\section{Introduction}

\subsection{Definition}

Carbon-based thin films possess unique and adjustable combination of properties such as high hardness, wear resistance, chemical resistance and good tribological performances. Among critical variables to tailor carbon thin film's properties for specific application are the distribution of the carbon hybridization states ( $s p^{1}, s p^{2}, s p^{3}$ bonds), the atomic $\mathrm{H}$ content, the content in dopants such as Si, F, N, B and O. Several types of carbon and carbon-based thin films are mentioned [1]:

(i) a-C and hydrogenated amorphous carbon $(\mathrm{a}-\mathrm{C}: \mathrm{H})$ films with a mixture of $s p^{2}$ and $s p^{3}$ bonding, highly $s p^{3}$-boned material (ta-C) and $s p^{2}$-bonded carbon

(ii) Carbon nitride $\left(\mathrm{a}-\mathrm{CN}_{x}\right)$

(iii) Metal/Amorphous carbon (a-C:M) composite films

Nanotribological and nanomechanics studies are essential in order to develop fundamental understanding of interfacial phenomena on a small scale in micro/nanostructures used in magnetic storage systems, micro/nanoelectromechanical systems (MEMS/NEMS), and other applications. In nanomanufacturing technology, many small-scale devices cannot be miniaturized further, because friction and wear appear to be exceedingly large in nanoscale machines. Many drawbacks seems to arise because the surface-to-volume ratio is large in small systems and thus surface forces such as friction become relatively large. The friction force at the nano-scale increases with the applied normal load and the tip size because of the increase in the contact area [2]. The friction at the nano-scale is governed mainly by its adhesive characteristics, but the friction at the micro-scale is greatly affected by the wear behavior since the asperity contacts are predominantly plastic and deformation is an important factor [2]. The lower frictional property of diamond-like carbon (DLC) at the nano-scale compared to that of Si-wafer is attributed to the smaller contact area and the lower adhesive force, which are affected by the lower interfacial energy.

The coefficient of friction $(\mathrm{CoF})$ represents, in principle, the friction between the structural material and diamond indenter probe. It is, in perspective, a dynamic rather than static, friction coefficient. In the contact-area-based approach, the CoF is decomposed into two components: shear (CoFS) and plowing (CoFP) [3,4]. The shear contribution is related to surface chemistry, whereas the plowing contribution is related to plastic deformation of the sample. Many theoretical studies and, most recently, an increasing number of experiments indicate that shear forces can be tremendously small between two atomically flat surfaces. These findings spur the hope for new avenues to reduce friction in nanoscale applications [5]. The last two decades, the frictional behavior of a single-asperity contact can be studied due to the introduction of new experimental tools (Atomic Force Microscopy, Lateral Force Microscopes), which made the nanometer and atomic scales accessible to tribologists [6-10]. It is the hope that once the atomic-scale manifestations of friction at such a nanometer-sized single asperity have been clarified, macroscopic friction could be explained with the help of statistics, i.e., by the summation of the interactions of a large number of small individual contacts, which form the macroscopic roughness of the contact interface [10]. A unified and clear understanding behind the 
mechanism of nano-scale friction is yet to be achieved. Given the importance of this topic, driven by the development of nanotechnology, the need for continued research effort in nano-tribology remains.

\subsection{Scientific Fundamentals}

When two solid bodies contact each other and one body begins to slide against the other, a frictional phenomenon appears. The friction force is defined as the drag against sliding, appearing along the contacting surfaces. According to the relative motion of two bodies, the friction forces are classified into static and dynamic ones, having different physical origins. The static friction force is characterized by the maximum force necessary to begin to slide one body against the other, whereas the dynamic friction force is the force applied to continue to slide one body against the other with a finite velocity (the energy must be dissipated during sliding). Experimentally, it is known that the dynamic friction force depends less on the sliding velocity.

Carbon-based thin films possess unique and adjustable combination of properties such as high hardness $(\mathrm{H})$ and elastic modulus $(\mathrm{E})$, wear resistance, chemical resistance and good tribological performances. Among critical variables to tailor a-C film's properties for specific application are the distribution of the carbon hybridization states $\left(s p^{1}, s p^{2}, s p^{3}\right.$ bonds), the atomic $\mathrm{H}$ content, and the content in dopants such as Si, F, N, B and O.

Diamond related materials (i.e., carbon nitride and cubic boron nitride [c-BN]) are some of the harder materials known and provide advantageous properties (e.g., high mechanical strength, chemical inertness, and very attractive friction and wear properties). Most of these superhard materials provide optical transparency, enhanced refractive index and excellent thermal conductivity, to name a few. All the aforementioned qualities make diamond, DLC, and other related materials ideal candidate materials in the industrial field $[1,11,12]$.

Carbon-based thin films have been developed to address a broad range of film applications, including one that demands outstanding tribological performance in a wide variety of operating environments. Carbon can adopt a large number of stable forms because of its ability to hybridize in multiple stable bonding states and to bond strongly with many other atoms. In addition to tailoring the hybridization state and the atomic $\mathrm{H}$ content, various dopants, such as $\mathrm{Si}, \mathrm{N}, \mathrm{B}, \mathrm{F}, \mathrm{O}$, can be used to modify the surface energy, electrical, and mechanical properties. Amorphous carbon (a-C) is a disordered material with short range order, which is directly related to the optical and electric properties. The interatomic distances and interbonding angles can significantly deviate from those of the crystalline fully $s p^{2}$-( $s p^{3}-$ ) bonded graphite (diamond) lattice, since a-C contains mixtures of hybrid bonding states $\left(s p^{1}, s p^{2}, s p^{3}\right)$. Amorphous carbon (a-C) films possess a unique and adjustable combination of properties such as high hardness, wear resistance, chemical resistance and good tribological performances. They have low CoFs and provide protection for the counterparts [11,12-16].

Hydrogenated amorphous carbon (a-C: H), also called DLC (in literature some definitions of DLC can be found, i.e., a-C:H including $s p^{3}$ bonds -even very few-, a-C:H which is predominantly $s p^{3}$ bonded etc.), is an amorphous network composed of carbon and hydrogen. This network consists of strongly cross-linked carbon atoms with mainly $s p^{2}$ (graphitic-like) and $s p^{3}$ (diamond-like) bonds.

The properties of these films depend strongly on the hydrogen content and the $s p^{3} / s p^{2}$ ratio, which in turn, depend on the deposition process and its parameters. Another subclass of DLC, the tetrahedral 
amorphous carbon films (ta-C), are hydrogen free and the carbon atoms are mostly $(>80 \%)$ carbon $s p^{3}$ hybridized. The ta-C films are mainly produced from pure carbon targets by filtered vacuum arc or by pulsed laser deposition. Considerable research effort has been dedicated to the study of tribology, over many decades. This has been driven by the importance of mechanical devices in an array of modern era applications. A readily observable technological trend is toward miniaturization and there has been a lot of discussion about the possibility of producing mechanical devices with dimensions measured at the micro/nano-scale [17]. There has been a clear trend toward smaller electronic devices, which has driven the development of techniques for micro-fabricating Si and the production of MEMS (e.g., data recording head and accelerometer). Nevertheless, the further development of MEMS and particularly moving mechanical arrays (MMA) has been restricted due to the poor tribological properties of Si. It is essential for many MEMS components to have a low friction and low wear surface. Until recently, little work has been devoted to nanotribology and this is perhaps partially due to the lack of effective test methods that are relevant to the operational conditions of proposed MEMS devices, in which case loads of a few micro/milli-Newtons are typical at contact areas and moving distances of a few microns, contact pressures of tens to hundreds of MPa with wear depths limited to nm [18-20]. There is a limited relevance to the use of macro-scale testing for predicting nanoscale behavior [21]. Advances of microelectromechanical system technology in the past decade render the understanding of scale effects in tribology especially important, because surface to volume ratio grows with miniaturization and surface phenomena dominate. Microscale and nanoscale friction force measurements can be obtained with various instruments, such as friction force microscope, atomic force microscopy, and scratch test with apparatus able to make finely controlled low-load scratches (in the range of $\mathrm{nN}-\mu \mathrm{N}$ ) [22-26]. In Figure 1, the compositions of the various forms of amorphous $\mathrm{C}-\mathrm{H}$ alloys on a ternary phase diagram with a hardness map are presented [11].

Figure 1. Different compositions of common carbon-based materials in correspondence with hardness and coefficient of friction $[1,11]$.

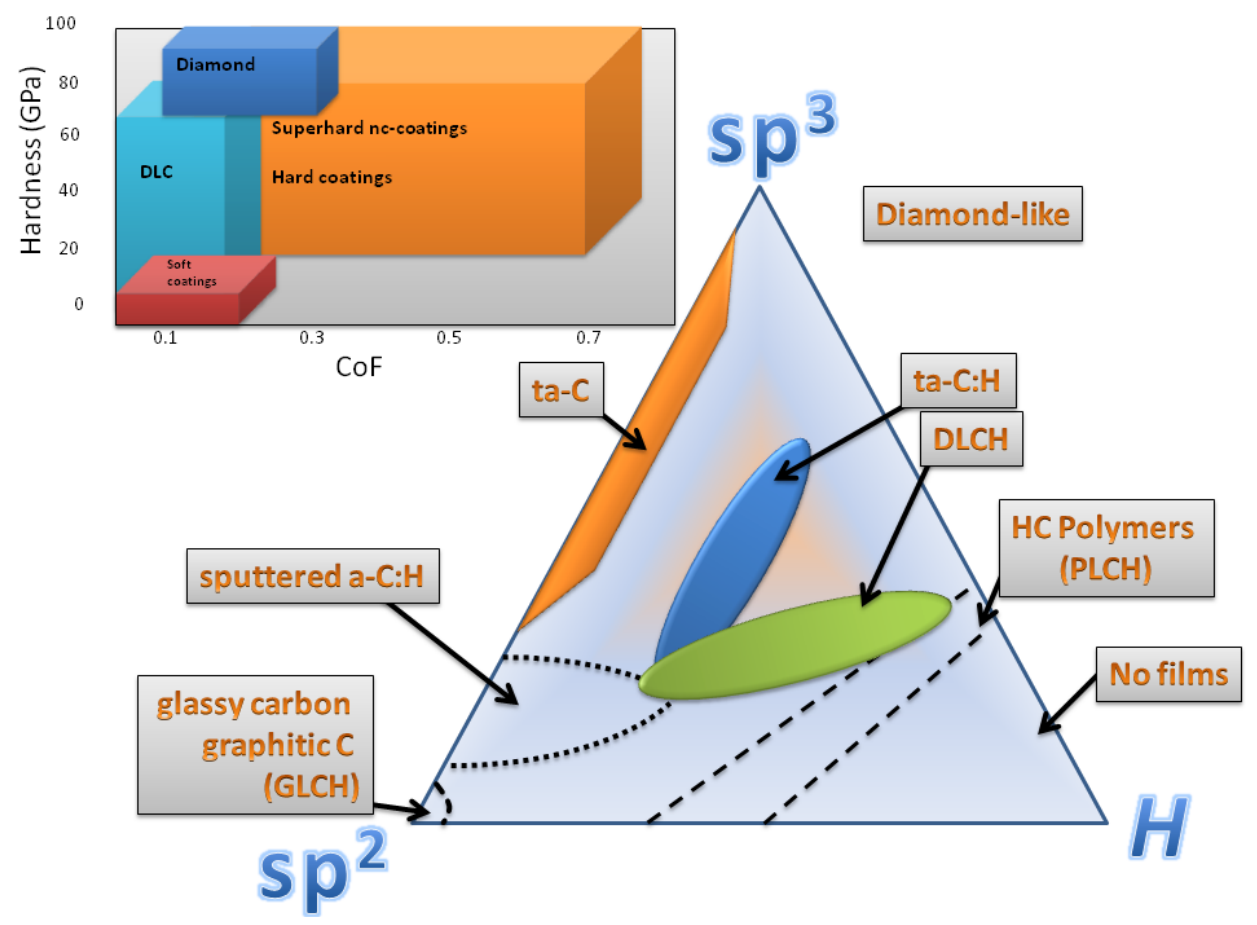


In many studies, continuum mechanics appears to provide an accurate description of the nanometer-scale contact area and other contact properties of carbon based thin films. Homogeneity, isotropy, linearity, and elasticity of the materials are important parameters to consider (several modified continuum contact mechanical models describing other cases have been applied). On the other hand, the current experimental testing systems exhibit significant difficulties in providing results in nanoscale (at a few $\mathrm{nm}$ ). The difficulties with experimental methods at very small depths can, in general, be easily resolved by using atomistic simulations to solve a variety of problems at the nano scale and to simulate experiments. Defining contact area is one of the major challenges for understanding friction in nanoscale contacts of carbon based structures. Widely in the literature, friction laws are established in nanoscale contacts by large-scale Molecular Dynamics (MD) simulations with realistic force fields (absence - or not - of van der Waals forces). Many challenges can be overcome by MD simulations in order to identify atomistic phenomena underlying friction. By understanding friction at the atomic level, it is possible to build a useful design strategy for the development of low-friction technology. For instance, as reported by MD simulations, adhesion between the probe and the carbon film increases the calculated friction, while tribochemical reactions within the film led to a restructuring of the film and a reduction in friction [27,28]. In addition, there is actually no standard that relates adhesion and friction, which means that range of expected reduction in friction per unit reduction of adhesion, is not known.

\section{Discussion}

\subsection{Surface Chemistry}

The low macroscopic friction of diamond in air $(\mu=0.05-0.1)$ has been attributed to the passivation of the surface by $-\mathrm{H}$ and $-\mathrm{OH}$ groups and/or by the production of lubricious $s p^{2}$-bonded species. Nanotribology studies put these ideas to the test, and a significant recent success has been the clear demonstration that $-\mathrm{H}$ termination reduces nanoscale friction dramatically [29]. Removal of the $\mathrm{H}$ from the surface causes an increase in the average CoF by more than two orders of magnitude compared with the $H$-terminated surface; dangling bonds can bridge an interface and increase the contribution of adhesion to friction, and passivation of those reactive bonds can reduce those forces in a dramatic way.

Comparing many other a-C:H thin films from Plasma Enhanced Chemical Vapor Deposition (PECVD), High-Density Plasma (HDP) and other Ultra High Vacuum (UHV) processes, a threshold (not constant) in hydrogen content can be evidenced for each process between superlow friction, at high hydrogen content, and high friction, at low hydrogen content, attributed to differences in the structure of the films, especially different amounts of hydrogen unbounded to carbon and the presence of aromatic clusters. Hydrogen amount on the surface has an effect on the interactions between contacting surfaces. In the film, it will have an effect on the cross-linking of the random network of carbon atoms. Increase of hydrogen content usually leads to more "polymer-like" structures, with high fraction of $\mathrm{C}-\mathrm{H} s p^{3}$ bonds, but such tendency is also strongly dependent on deposition process. Adhesion results in loss of superlow friction, probably due to interactions between the $\pi$-orbitals of $s p^{2}$ carbon atoms. Essentially, in order to achieve superlow friction, one has to control the composition of 
the sliding surfaces as well as the rheology of the transfer film [30]. Either the hydrogen content of the pristine a-C:H film is sufficient to avoid $s p^{2}$ carbon interactions, providing also a viscoplastic character to the film which probably helps in transfer film growth, or one has to feed the a-C:H and transfer film surface with hydrogen to avoid adhesive interactions and to modify the interfacial material, in order to allow a "healing" effect on the damaged surfaces. Oxygen might act in a selective removal process of $s p^{2}$ carbon atoms. However, at higher pressures of oxygen, the removal of the transfer film is almost complete, leading to $\mathrm{CoF}$ in the $0.2-0.3$ range (role of the transfer film on friction reduction) [31].

The tribological behavior of carbon-based thin films is strongly affected by their chemical composition, polycrystalline structure and surface morphology [32]. In all environments, the tribological behavior of carbon thin films is controlled by an interfacial transfer layer formed during friction. The aforementioned layer is formed by a friction-induced modification of the top layer of the film into a material of low shear strength. Despite this comprehension at a macroscopic scale, very little is reported on the mechanisms that control friction at a nanoscopic level. In addition, it has been demonstrated that for graphite and hydrogenated carbon films the macro-tribological behavior is not directly comparable with the nanotribological one, due to dependence of wear, plastic deformation and delamination on the contact area [32]. For the case of a- $\mathrm{CN}_{x}$ films, higher $\mathrm{CoF}$ is attributed to the fact that $\mathrm{N}$ atoms change the polycrystalline structure of the carbon films and thus the number of phonon modes available for excitation. The improved properties of the a- $\mathrm{CN}_{x}$ films are attributed to a "fullerene-like" microstructure with curved and intersecting basal planes. The determination of this "fullerene-like" microstructure being responsible of a lower $\mathrm{CoF}$ at a nanoscopic scale, could be performed through molecular dynamics calculations.

\subsection{Bulk Chemistry-Additives}

The changes in the structure, composition and mechanical properties of the film with increasing additive content may take important positions in controlling the film friction and wear behavior. Especially, the bonding ratio of film among several factors, which might take important positions in controlling the wear behavior, would be the main reasons for its low CoF and better wear resistance [33]. It is generally believed that an increase of bonding ratio $\left(s p^{3} / s p^{2}\right)$ might increase wear resistance, but separate study is difficult since it is difficult to grow films that vary one of these independently of the other [34]. While the amount of $\mathrm{H}$ and the $s p^{3} / s p^{2}$ bonding ratio influence nanotribology, detailed comprehensive studies necessarily involve varying these parameters independently to elucidate their individual contributions to the mechanical and tribological behavior.

In need of superhard and yet tough ceramic films, a-C-based films prove to be good candidates [35]. Bias graded deposition creates a graded bonding structure such that the $s p^{2}$ hybridization become more intense towards the substrate-film interface to provide better toughness and adhesion while $s p^{3}$ bonding gets more intense towards the surface of the film to render higher $\mathrm{H}$ for tribological performance. Co-sputtering of $\mathrm{Al}$ with graphite embeds elemental $\mathrm{Al}$ into a-C to form a-C(Al) film which is reported to greatly reduce growth-induced stresses acquired during deposition, at the expense of $\mathrm{H}$ because of the reduction in the amount of $s p^{3}$ bonding. Co-sputtering of Ti and Al with graphite produces nc-TiC to embed in a-C(Al) matrix, while formation of nc-TiC helps partially restore the hardness lost due to doping of Al. Comparing with a-C film deposited under constant substrate bias, the bias-graded 
deposition leads to less friction and improves adhesion of amorphous carbon by twofolds [35]. Nanocrystalline TiC embedding in amorphous carbon results in an increase of adhesion up to four times with a slight increase in $\mathrm{CoF}$. The incorporation of $\mathrm{Al}$ in the amorphous carbon matrix results in an increase of adhesion strength and reduces the $\mathrm{CoF}$ by $20 \%$ [35]. Under ambient condition, the nanocomposite films exhibit higher friction than a-C films while under oil lubrication the nanocomposite films experience less friction. For nc-TiC/a-C(Al) film, a low CoF of only 0.04 is revealed. The incorporation of $\mathrm{F}$ has been found to alter the hydrophobicity of DLC films, and this also influences the frictional characteristics. Using a Chemical Vapor Deposition (CVD) process, increasing the $\mathrm{F}$ concentration increases the water contact angle (from $72-95^{\circ}$, as $\mathrm{F}$ content is increased from $0 \%-35 \%$ ) [36]. In literature, adhesion and friction measured by Atomic Force Microscopy (AFM) in air decreases with increasing contact angle. The reduced adhesion is attributed to the reduction of capillary interactions, but the presence of a capillary has not been observed directly. Regardless, this demonstrates the important effect that adhesion forces have on nanoscale friction. Numerous significant studies of literature have lead to new perspectives, indicating that for hard carbon systems, surface chemistry dominates the tribology in the wearless regime, while bulk chemistry matters more after the wear threshold has been reached.

In Figure 2 a schematic representation of the $\mathrm{CoF}$ ranges for a-C, ta-C, a-CN $\mathrm{N}_{x}$ and various DLC films along with chemical structure embedded. Data presented in Figure 2 are based on Table 1, where tribological properties of carbon-based thin films deposited by various methods are presented according to literature studies.

Figure 2. Schematic representation of the $\mathrm{CoF}$ ranges for a-C, ta-C, a-CN $\mathrm{CN}_{x}$ and DLC films along with chemical structure embedded, according to Table 1.

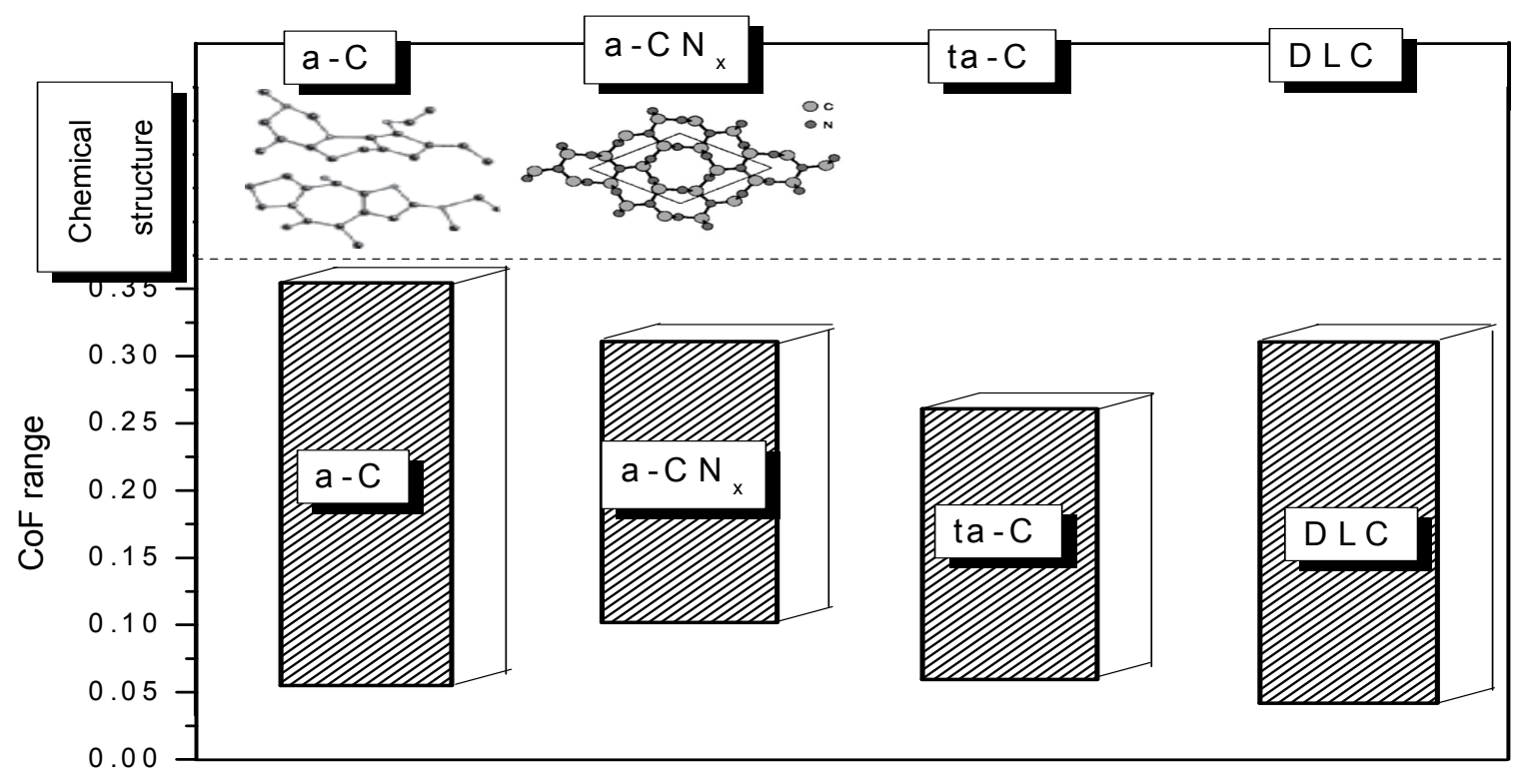


Table 1. Tribological properties of carbon-based thin films deposited by various methods.

\begin{tabular}{|c|c|c|c|c|c|c|}
\hline Carbon Thin Film Type & $\begin{array}{c}\text { Deposition } \\
\text { method }\end{array}$ & $\begin{array}{c}\text { Thickness } \\
(\mathbf{n m})\end{array}$ & $\begin{array}{l}H^{3} / \mathbf{E}^{2} \\
(\mathrm{GPa}) \\
\end{array}$ & H/E & CoF at Lo & $(\mathrm{mN})$ \\
\hline \multirow{2}{*}{ a-C $s p^{3}$ rich multilayer [37] } & \multirow{2}{*}{ MS } & 90 & 0.235 & 0.093 & 0.25 & \\
\hline & & 274 & 0.44 & 0.1231 & 0.2 & \\
\hline a-C multilayer [38] & MS & 115 & 0.383 & 0.1263 & & \\
\hline $\mathrm{a}-\mathrm{C} s p^{3}$ rich [37] & MS & 30 & 0.1704 & 0.0973 & & \\
\hline a-C $s p^{2}$ rich [37] & MS & 30 & 0.0303 & 0.0615 & 0.35 & 0.35 \\
\hline a-C $s p^{2}$ rich [37] & $\mathrm{EB}$ & 30 & 0.01 & 0.05 & & \\
\hline a-C [37] & UBMS & & 0.4087 & 0.1148 & 0.25 & 0.25 \\
\hline \multirow{2}{*}{$\mathrm{a}-\mathrm{C}: \mathrm{H}[39]$} & \multirow{2}{*}{ PECVD } & 1140 & 0.2244 & 0.125 & & \\
\hline & & 550 & 0.3347 & 0.1343 & & \\
\hline ta-C [1] & S-bend & & 0.649 & 0.123 & 0.05 & \\
\hline ta-C [1] & FCVA & 70 & 0.3704 & 0.111 & 0.1 & \\
\hline ta-C:H [40] & EC & 70 & 1.389 & 1.167 & $0.01-0.12$ & $1-20$ \\
\hline $\mathrm{a}-\mathrm{CN}_{x}[38]$ & MS & 222 & 0.2142 & 0.109 & $0.1-0.3$ & $1-20$ \\
\hline ta-C $[41]$ & FCVA & 76 & 0.8935 & 0.1057 & $0.1-0.15$ & $1-20$ \\
\hline \multirow{3}{*}{ ta-C [42] } & \multirow{3}{*}{ PLD } & 120 & & & 0.07 & \\
\hline & & 130 & & & 0.07 & \\
\hline & & 210 & & & 0.11 & \\
\hline DLC:Ti [41] & CFUMS & 1000 & 0.2944 & 0.1056 & $0.1-0.4$ & $1-80$ \\
\hline DLC:Mo [43] & MS & 650 & 0.2203 & 0.1192 & & \\
\hline DLC:Silver [44] & PECVD & 500 & & & $0.17-0.24$ & $1-20$ \\
\hline ta-C $[45]$ & FCVA & 50 & 0.2518 & 0.07 & $0.08-0.14$ & $1-5$ \\
\hline ta-C [46] & OPBD-FCVA & \multirow{3}{*}{280} & 0.861 & 0.1071 & & \\
\hline \multirow{2}{*}{$\mathrm{a}-\mathrm{CN}_{x}[45]$} & \multirow{2}{*}{ MS } & & 0.0274 & 0.07 & & \\
\hline & & & 0.1292 & 0.085 & & \\
\hline ta-C multilayer [46] & OPBD-FCVA & & 0.8137 & 0.144 & 0.12 & \\
\hline $\mathrm{a}-\mathrm{C}[47]$ & CFUBMS & 200 & 0.3456 & 0.12 & 0.1 & \\
\hline $\mathrm{a}-\mathrm{C}: \mathrm{H}[48]$ & PIII & 70 & & & $0-0.6$ & $0-14$ \\
\hline a-C:Ti [49] & PCVD & 500 & & & $0.05-0.1$ & $1-200$ \\
\hline \multirow{4}{*}{ ta-C:Si [46] } & \multirow{4}{*}{ FCVA } & 5 & & & 0.23 & \\
\hline & & 20 & & & $0.12-0.24$ & $1-18$ \\
\hline & & 60 & & & $0.12-0.3$ & $1-18$ \\
\hline & & 80 & & & $0.1-0.25$ & $1-7$ \\
\hline \multirow{2}{*}{$\mathrm{a}-\mathrm{CN}_{x}[50]$} & \multirow{3}{*}{ FCVA } & 100 & 3.502 & 0.232 & & \\
\hline & & 100 & 1.6 & 0.2 & & \\
\hline \multirow{3}{*}{$\mathrm{a}-\mathrm{C}[51]$} & & 29 & 2.185 & 0.236 & $0.15-0.25$ & $25-300$ \\
\hline & \multirow[t]{2}{*}{ Sputtering } & 46 & 2.687 & 0.251 & $0.22-0.28$ & $25-200$ \\
\hline & & 85 & 1.643 & 0.208 & $0.2-0.3$ & $25-400$ \\
\hline
\end{tabular}


Table 1. Cont.

\begin{tabular}{|c|c|c|c|c|c|c|}
\hline DLC:9Cr18 & Vacuum Magnetic- & 500 & 0.121 & 0.059 & $0.15-20$ & $0-180$ \\
\hline DLC:40CrNiMo [52] & $\begin{array}{c}\text { Filtering Arc Plasma } \\
\text { Deposition }\end{array}$ & 500 & 0.185 & 0.064 & $0.15-40$ & $0-84$ \\
\hline $\mathrm{a}-\mathrm{C}$ & PVD & & $0.15-0.5$ & 0.1 & & \\
\hline $\mathrm{a}-\mathrm{C}: \mathrm{H}$ & PACVD & & $0.48-0.37$ & $0.14-0.11$ & & \\
\hline $\mathrm{a}-\mathrm{CN}_{x}[53]$ & PACVD & & $0.1-0.18$ & 0.1 & & \\
\hline $\mathrm{a}-\mathrm{CN}_{x}$ & RF Snutterino PFCVD & $250-400$ & $0.1-0.18$ & 0.1 & & \\
\hline DLC [54] & К厂 sputterning PLC VD & $250=400$ & 0.315 & 0.108 & & \\
\hline DLC: $\mathrm{Al}_{2} \mathrm{O}_{3}-\mathrm{TiC}$ ceramic (AlTiC), & PECVD & & 0.099 & 0.062 & 0.06 & \\
\hline DLC:Si $\left(\begin{array}{lll}1 & 0 & 0\end{array}\right)$ & PECVD & 250 & 0.687 & 0.1625 & 0.052 & 150 \\
\hline DLC:fused silica and & PECVD & 250 & 4.88 & 0.4333 & 0.045 & 150 \\
\hline DLC:SU8 photoresist [55] & PECVD & & 7.29 & 0.9 & 0.037 & \\
\hline a-C:F:H & RF-PECVD & & 0.111 & 0.1053 & 0.15 & \\
\hline $\mathrm{a}-\mathrm{C}: \mathrm{F}: \mathrm{N}: \mathrm{H}[56]$ & RF-PECVD & 400 & 0.047 & 0.079 & 0.13 & $0.01-0.12$ \\
\hline DLC:c-Si [57] & PECVD & & & & $0.2 / 0.3$ & \\
\hline a-C (H: 28.1 GPa) & & & & & 0.15 & \\
\hline bias-graded a-C (H: 25.1 GPa) & DC Magnetron & 1 to 16 um & & & 0.14 & \\
\hline nc-TiC/a-C (H: 27.4 GPa) & Sputtering & 1 to $1.6 \mu \mathrm{m}$ & & & 0.22 & \\
\hline nc-TiC/a-C(Al) (H: 19.6 GPa) [29] & & & & & 0.18 & \\
\hline Si-DLC (0 at.\%) & & 1000 & & & 1.6632 & \\
\hline Si-DLC (1.0 at.\%) & RFPACVD & 1000 & & & 1.0189 & 2000 \\
\hline Si-DLC (2.0 at.\%) [33] & & 1000 & & & 0.5895 & \\
\hline \multirow{2}{*}{$\mathrm{Cr} / \mathrm{a}-\mathrm{C}[58]$} & Unbalanced Magnetron & 2000 & 0.1766 & 0.097 & & \\
\hline & Sputter & 149 & 0.2298 & 0.111 & & \\
\hline $\mathrm{DLC} / \mathrm{C} 40$ & PVD-CVD & & & & 0.15 & \\
\hline DLC/Ni 50\% Cr & PVD-CVD & & & & 0.1 & \\
\hline $\mathrm{DLC} / \mathrm{Al}_{2} \mathrm{O}_{3}-13 \% \mathrm{TiO}_{2}$ & PVD-CVD & & & & 0.65 & 1000 \\
\hline DLC/WC-Co [59] & PVD-CVD & & & & 0.1 & \\
\hline DLC $[60]$ & Linear Ion Beam & 2.2 & 0.0222 & 0.0666 & & $0.2-12.8$ \\
\hline nc-Ti $(\mathrm{N}, \mathrm{C}) / \mathrm{a}-\mathrm{C}: \mathrm{H}$ & Pulsed DC & 400 & & & & \\
\hline $31.1 \mathrm{H}$ at.\% & magnetron & & 0.1370 & 0.099 & 0.21 & \\
\hline $42.6 \mathrm{H}$ at. $\%$ & Sputtering & & 0.0774 & 0.0957 & 0.25 & \\
\hline $47.3 \mathrm{H}$ at. $\%$ [61] & & & 0.0359 & 0.0847 & 0.35 & \\
\hline Ti-DLC/alumina & ClosefieldUnbalanced & 1000 & 0.2944 & 0.1056 & $0.12-0.25$ & $5-10$ \\
\hline Ti-DLC/steel [43] & MS & & & & & \\
\hline a- $\mathrm{CN}_{x}-\mathrm{TiN}_{x} / \mathrm{G} / \mathrm{Ti}$ ratio & PLD & 1200 & & & & \\
\hline Pure Ti & & & 0.1613 & 0.0872 & 0.34 & \\
\hline 0.5 & & & 0.1587 & 0.0821 & 0.24 & \\
\hline
\end{tabular}


Table 1. Cont.

\begin{tabular}{|c|c|c|c|c|c|c|}
\hline 1 & & & 0.1968 & 0.08651 & 0.19 & 980 \\
\hline 2 & & & 0.2071 & 0.0874 & 0.17 & \multirow{5}{*}{ 900-2000 } \\
\hline Pure graphite [62] & \multirow{3}{*}{ ECR-CVD } & \multirow{3}{*}{$630-1150$} & 0.2021 & 0.0858 & 0.11 & \\
\hline a-C:H polymerlike & & & 0.007 & $0.05-0.08$ & 0.4 & \\
\hline $\mathrm{a}-\mathrm{C}: \mathrm{H}$ fullerenelike [63] & & & 0.012 & $0.06-0.12$ & 0.1 & \\
\hline \multirow{4}{*}{$\mathrm{aCN}_{x} / \mathrm{TiN}[64]$} & \multirow{4}{*}{$\begin{array}{l}\text { Pulsed laser } \\
\text { deposition }\end{array}$} & $\mathrm{aCN}_{x} \operatorname{TiN}$ & & & & \\
\hline & & 2528 & 0.2636 & 0.0938 & 0.28 & \multirow{16}{*}{$500-8500$} \\
\hline & & 3321 & 0.1924 & 0.0877 & 0.16 & \\
\hline & & 4212 & 0.1799 & 0.0884 & 0.13 & \\
\hline \multirow{2}{*}{\multicolumn{3}{|c|}{$\begin{array}{l}\text { a-CN } \mathrm{CN}_{x} \text { on Ti-TiN/CN } \\
\text { gradient underlayer }\end{array}$}} & & & & \\
\hline & & & 0.32308 & 0.11042 & 0.123 & \\
\hline M1 & & & 0.30977 & 0.11043 & 0.115 & \\
\hline M2 & & & 0.19287 & 0.09471 & 0.109 & \\
\hline M3 & \multicolumn{2}{|l|}{ Direct Current } & 0.14146 & 0.08698 & 0.108 & \\
\hline M4 & Magnetron & 180 & & & & \\
\hline a- $\mathrm{CN}_{x}$ on $\mathrm{Ti}$ interlayer & \multirow[t]{5}{*}{ Sputtering } & & 0.22401 & 0.09956 & 0.223 & \\
\hline $\mathrm{P} 1$ & & & 0.15602 & 0.08945 & 0.218 & \\
\hline $\mathrm{P} 2$ & & & 0.07756 & 0.07097 & 0.205 & \\
\hline P3 & & & 0.04585 & 0.06131 & 0.207 & \\
\hline M4 [65] & & & 0.04503 & & & \\
\hline DLC:glass & \multirow{2}{*}{ RF-PECVD } & \multirow{2}{*}{100} & 0.1814 & 0.12 & & \\
\hline DLC:silicon [66] & & & 0.13 & 0.1 & & \\
\hline
\end{tabular}

\subsection{Applied Load Effect}

Several single asperity nanotribological studies of carbon-based materials have been performed in the literature [30]. In case of carbon-based measurements, tip selection is mandatory. However, commercial tips are typically composed of diamond, $\mathrm{Si}$ or $\mathrm{Si}_{3} \mathrm{~N}_{4}$, with only a few other coated tips available. Several coated tips are reported in literature; the benefit of film tip with the same material as the sample is the matching of the interface that would be found in an actual device composed entirely of that material. In this case, further modeling and experimental work is required to clarify the exact role that contact area plays at the nanoscale. Despite the important insight into the tribological properties of carbon-based films derived from previous studies, relatively less attention has been paid on the friction behavior and films deformation mode dependence on the applied normal load, especially in the case of carbon-based thin films subjected to low normal loads [67]. The influence of the normal load (from 2 to $20 \mathrm{mN}$ ) on the friction of amorphous carbon nitride $\left(\mathrm{CN}_{x}\right)$ films grown on Si (100) substrates by reactive ion sputtering and energetic ion bombardment during deposition (IBD) is studied in [68]. In Figure 3 the nanotribological performance of carbon-based thin films (dependence of CoF on the applied load), according to Table 1, is presented. 
Figure 3. Dependence of CoF on the applied load for carbon-based thin films, according to Table 1.
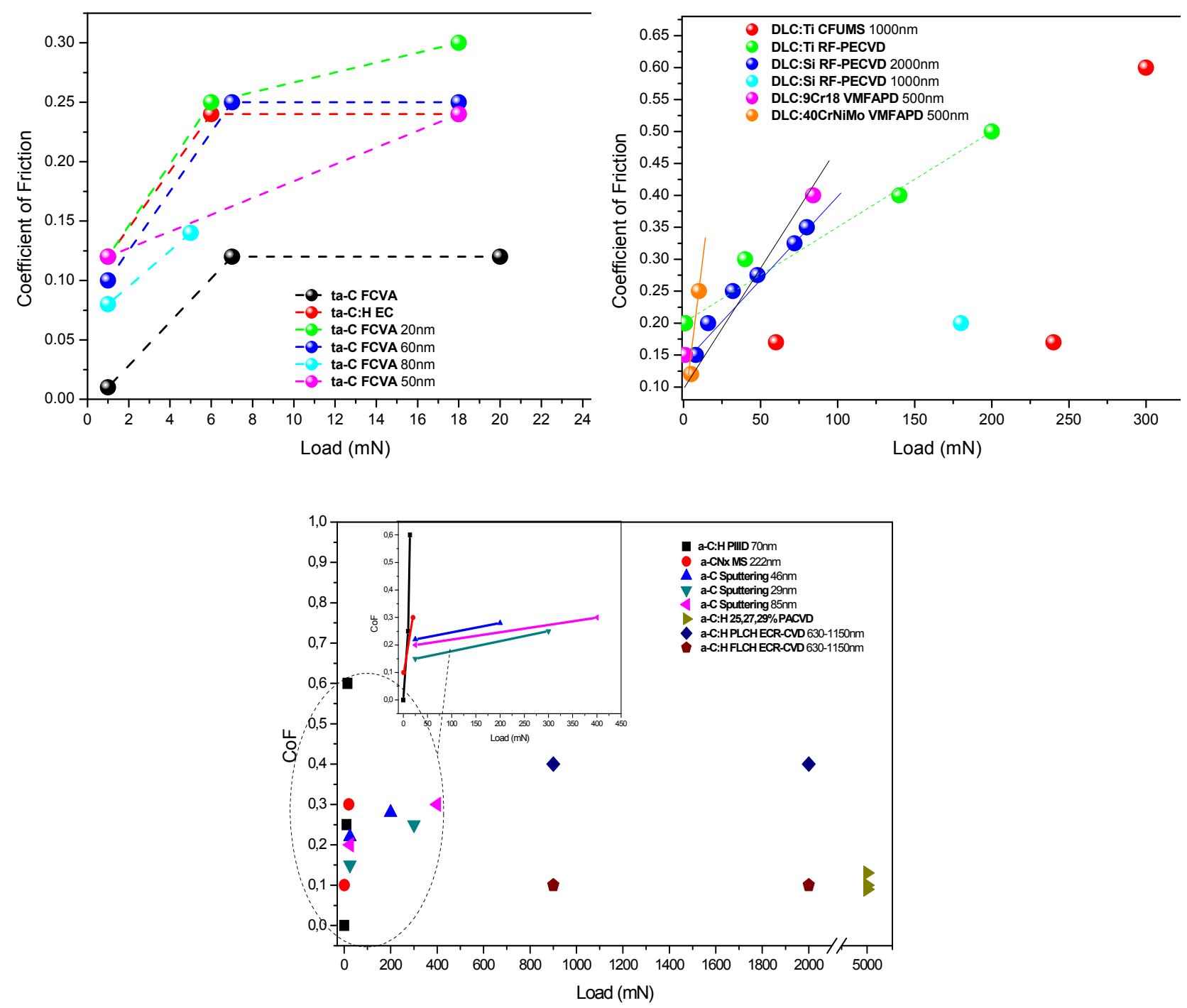

The mechanical and tribological properties of ta-C films are closer to those of bulk diamond than the a-C coatings. Hydrogenated a-C films in principle show a higher coefficient of friction than the a-C and ta-C materials due to the significant amount of hydrogen and differentiation of $s p^{3}$ bonding structures.

The tribological characteristics of interface strongly depend on orientation, topography, chemical composition, bonding structure, elastic/plastic properties, and environment. In case of physical origins of friction and energy dissipation determination, precise measurements of these factors must be considered [32].

Applications involving sliding and/or contacting surfaces require certain properties of film, such as resistance to fracture, low friction and low wear properties, which are determined through measurement of key physical properties such as $H, E$ and surface roughness due to the relationships between these physical and the desired tribological properties. Film adhesion and fracture susceptibility of the film-substrate couple is commonly determined through scratch test for critical load investigation. 


\subsection{Orientation Effect in Crystalline Diamond}

At the macroscopic scale, diamond single crystals show strong orientation effects (friction and wear depend on both the surface orientation and the sliding direction), whereas at the nanoscale the findings are considerably different (attributed in part to wear avoidance, but it may also be as a result of an enhanced influence of local atomic interactions). In several studies performed on single-crystal, H-terminated diamond (111) and (001) surfaces with a quite low diamond tip radius, no difference in average friction force values was observed between the two surfaces except for qualitative differences in the friction images, attributable to the different lattice spacing and orientations $[69,70]$.

The high CoFs of rough diamond films with (111) orientation can be attributed to the abrasive cutting and plowing effects of sharp surface asperities on the softer counterface pins. If a favorable (100) growth orientation is present, such films can also afford low CoFs to sliding surfaces, despite relatively higher measured surface roughness. In general, previous studies confirmed that regardless of the grain size, diamond films with a smooth surface finish provide very low friction to sliding counterfaces. Apart from physical roughness and chemical passivation effects, phase transformation or structural changes can also play a major role in the friction and wear performance of carbon thin films. The extent of such changes can be dominated by environmental species or by ambient temperature. Phase transformation can readily occur even in natural diamond [71] when extreme contact pressures and/or high frictional heating are present at local asperity levels. Real contact occurs first between these asperities, and their tips can either fracture or undergo phase transformation because of the extreme pressures and high frictional heating. Thermodynamically, graphite is the most stable form of $\mathrm{C}$, whereas diamond is metastable. It is also known that when excited thermally or by ion bombardment, diamond can transform to a graphitic form $[72,73]$. The graphitic debris particles can gradually accumulate at the sliding contact interface and then begin to dominate the long-term sliding friction and wear performance of these films. Most of the debris particles derived from sliding diamond surfaces exhibit a graphitic microstructure [39,40]. Raman Spectroscopy, Electron Diffraction, Electron Energy Loss Spectroscopy, and Transmission Electron Microscopy have concurrently confirmed the presence of highly disordered graphitic debris particles at sliding contact interfaces [39].

\subsection{Film Thickness Effect}

The wear rate reduces with increasing applied load and more significantly with reducing carbon based thin film thickness. In certain cases a clear exponential reduction of specific wear rate with reducing film thickness over the range of 2000-10 nm occurs. The initial film thickness is of importance, since wear rate of thick films is not reported to decrease exponentially as the substrate approaches [74]. While a little change in film $H$ and $E$ with film thickness is revealed, the main mechanism of wear operating is ascribed to three-body abrasion, although fatigue fracture is thought to significantly contribute.

\subsection{Film Roughness Effect-Lubricant Use}

Although RMS surface roughness does not carry any information about slopes, sizes or frequencies of asperities, it is still an important parameter for predicting and understanding the properties of 
tribological systems [75]. Previous investigations with carbon films indicated that CoF increases with increase of roughness [76,77]. Extensive studies of friction dependence on the surface roughness report an increase, over a wide range of surface roughness, in the CoF with very smooth or very rough surfaces. Friction coefficient increase is attributed to real contact area excessive growing, whereas in the latter it is due to the need to lift one surface over the asperities of the other. In intermediate ranges of roughness, friction is at its minimum and does not depend on the roughness. In a ratchetting mechanism, relative motion between two surfaces is achieved by asperities riding over each other (asperities slope angle increase), leading to increase of CoF with increasing roughness [76]. In energy-loss mechanism, asperities push each other, resulting in increased CoF with roughness. In case of film surface polishing for roughness reduction, the film does not contain any such carbonaceous layer to transfer (friction coefficient does not vary with addition of lubricant). Additives are easily adsorbed on the surface of the film and able to form boundary lubrication, which is independent of the quality of the additives as the film is nanocrystalline and contains an exceptionally high amount of surface atoms. In case of higher temperature, adsorbed additives diffuse to the bulk of the film. In this case, presence of high amount of grain boundary and higher temperature augment the process of diffusion. The characteristic of the adsorbed boundary layer is altered and its functional structure and lubrication abilities are lost. When contact temperature is low, less diffusion of additives of the lubricant occurs to the bulk of the film and boundary lubrication forming with line contact is easier. If temperature rises at the contact point with ball contact, additives tend to diffuse to the bulk of the film due to high amount of grain boundary in nanocrystalline film. Thus, formation of boundary lubrication becomes difficult giving rise to increase in friction coefficient [78].

Figure 4 shows that ta-C films have ultra-low roughness (RMS roughness $\sim 0.12 \mathrm{~nm}$ ) and that are independent of the film's thickness, thus providing films equally smooth when 11 or $60 \mathrm{~nm}$ thick. These are unique properties since films usually form through a series of stages of nucleation, coalescence and possible roughening which, in general, lead to island formation for the thinnest films.

Figure 4. Correlation of roughness and thickness of ta-C films deposited with HCA and FCVA.

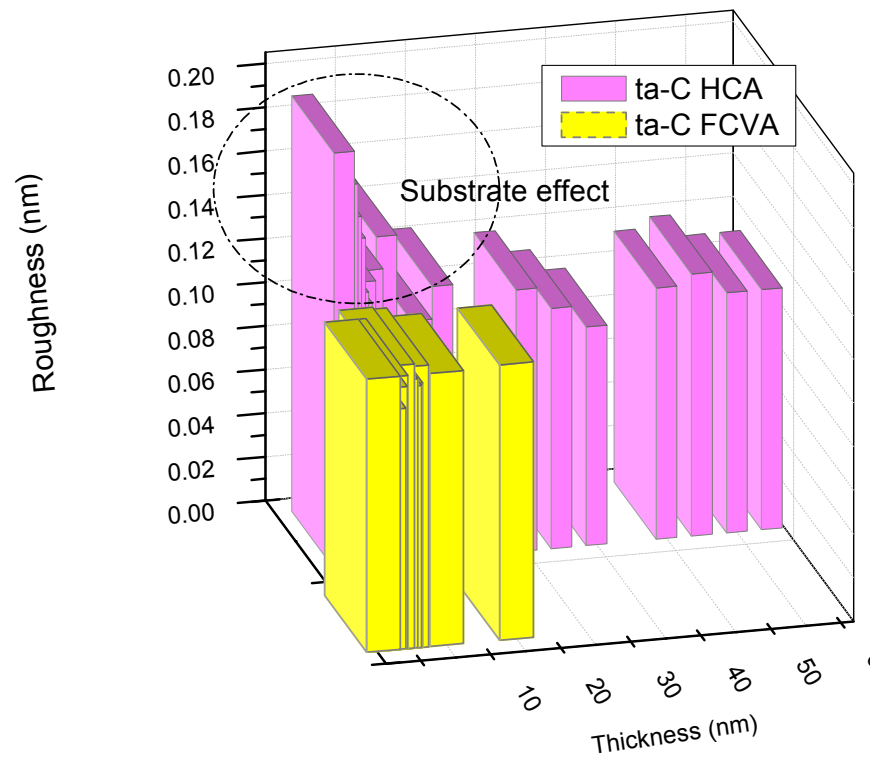




\subsection{Graphite-Superlubricity Effect}

When a tip is sheared over the surface of a crystal lattice, it often moves in an unstable "stick-slip" pattern that matches the lattice. This was first observed on graphite and has since been reported on many other materials including diamond [79], and it is attributed to energy storing of the compliance of the system (cantilever, tip, and contact zone) as shear is applied. When the lateral force (gradient in the sliding direction) drops below the net system stiffness, the essence of mechanical instability leads to sudden energy release. As lateral interaction force is necessarily periodic by virtue of the symmetry of the crystal surface, stick-slip behavior repeats once every lattice site, creating stunning images that match the lattice periodicity. In this case, the remaining frictional dissipation [70,80-82] is below recordable values and the phenomenon has been labeled (perhaps misleadingly) "superlubricity" (friction is dramatically lower). A key to achieve this transition to instability-free low friction is to obliterate the periodicity of the lateral potential by making the interface incommensurate. When deposited on atomically smooth or highly polished substrates (such as Si wafers or cleaved sapphire or mica surfaces), carbon films can attain the kinds of smoothness that are needed for eliminating the deleterious effects of surface roughness on friction. At thicknesses as low as $2-5 \mathrm{~nm}$, they provide very uniform coverage and mimic the original surface roughness of the underlying substrates. If necessary, the sliding surfaces of carbon films can be polished after the deposition. As for achieving a high degree of chemical inertness on sliding carbon surfaces, researchers have pursued two complementary or closely-related approaches. Specifically, they have either used a hydrogen-rich gas discharge plasma during film deposition [70,79,81-88] or they have introduced hydrogen gas into the test chamber during tribological testing [88-93]. The control of surface chemistry or chemical interactions at sliding DLC interfaces is extremely important for the friction and wear behavior of carbon-based thin films. Specifically, by controlling or effectively eliminating the intrinsic and extrinsic sources of friction in carbon films, one should be able to achieve ultra- and superlow CoF under both dry and lubricated sliding conditions [94].

\subsection{Effect of Environment}

Tribochemical reactions do occur, but physisorption of environmental species also plays a role [30]. An understanding of humidity effect of these materials nanoscopically is only beginning to emerge. Adhesion shows no dependence on relative humidity $(\mathrm{RH})$, indicating that the conventional picture of meniscus formation leading to higher friction and adhesion does not represent the mechanism at play in this system, as the adhesion should change with RH. Using hydrocarbon-coated tips, the frictional properties of diamond and amorphous carbon are found to differ between air (at $40 \%-60 \% \mathrm{RH}$ ) and dry Ar environments. Interfacial shear strengths are reported to be highest for a-C in air, followed by diamond in air, then a-C in dry $\mathrm{Ar}$, and finally diamond in dry $\mathrm{Ar}$ (adhesive forces are also lower subjected dry Ar environment). Higher friction in ambient conditions is attributed to the presence of water on the surface of the samples [30]. Wear and frictional behavior of carbon-based films rubbed against brass in water are reported to be affected by the water temperature and dissolved ions. Elevated temperature with frictional heat generation prevents the formation of intact and lubricious tribo-layer leading to higher friction and wear [95]. When adsorbed gases are removed from sliding diamond 
surfaces, friction increases rapidly because the dangling surface bonds are free and highly activated to form strong bonds across the sliding contact interface. Despite a large discrepancy in time and length scales, molecular dynamics simulation has provided significant insight into the extent of physical, chemical, and mechanical interactions that occur at sliding diamond interfaces on the atomic scale [1].

Sliding friction forces at nanometer scale are determined by two competitive processes. The first process is the thermally activated stick and slip behavior when friction is attributed to the adhesive forces between the two surfaces in contact. Additionally, capillary effects due to water vapor condensation must be taken into consideration, especially for tests performed in air.

\subsection{Effect of Substrate Material, Thickness and Roughness}

Other important factors are film thickness, substrate roughness, and substrate stiffness, as reported in literature [55,96-99]. For hard carbon films on substrates, of particular interest for hard-disk applications, numerous groups have reported that a critical film thickness (usually $>5 \mathrm{~nm}$ ) needs to be achieved for the film to exhibit the exceptional nanoscale friction and wear properties known to these materials [94]. Furthermore, the roughness and $E$ of the substrate can affect film properties. Consequently, according to the conformal way in which carbon films coat a substrate, substrate roughness is transferred to the film. Lower $E$ of the substrate can lead to bending under applied loads, which in turn may increase contact area and thus friction [55]. When film thickness reaches a practical lower limit, determining the intrinsic properties and likewise the functionality of the films for wear- and corrosion-resistant applications poses a challenge. The final film roughness of carbon films strongly depends on the surface roughness of the substrate. The films deposited on substrates with relatively low surface roughness showed an increase in the final film roughness values, due to the higher deposition rate at the peaks and the lower lateral growth at the valleys [100]. It has been observed that the formation of radial cracks precedes ring cracks in carbon films on the rougher steel substrates. Ring crack formation was delayed, and happened at higher loads for the rougher samples, due to the early formation of the radial cracks at the film-substrate interface, coupled with the plastic deformation of asperities on the surface of the film. The population of radial cracks at the interface of film and substrate is proportional to the relative substrate surface roughness, i.e., on the distribution of interfacial asperities.

\subsection{Tribological Properties: The Significance of Ratio H/E}

It is known that many of the mechanisms of film failure begin with or directly involve plastic deformation. Consequently, a particular concern in the usefulness of a-C films as protective overcoat materials in hard disk and/or wear-resistant applications is that these films must be highly resistant to plastic deformation during contact events [1]. The film has to undergo a high proportion of elastic deformation occurring when indenting, resulting in high values of $H$ (which reflect the small amounts of plastic deformation occurring), and not only high $H$ as is generally held. One possible way to extract the elasticity can occur via Johnson analysis for solids of revolution [101,102], taking into account the Tresca criterion ( $p_{0}=1.6 Y$, where $Y$ is the yield stress) and the Tabor relation $(H=3 Y)$, the load $\left(P_{y}\right)$ to initiate the yield (plastic deformation) is proportional to the term $\left(H^{3} / E^{2}\right): P_{y}=K\left(H^{3} / E^{2}\right)$. The term $H^{3} / E^{2}$ combines the $H$ and $E$ values of a material and sets the amount of elasticity exhibited by the 
film [1,102]. In Figures 5 and 6 schematic representations of the $H^{3} / E^{2}$ (1.0 for diamond) and $H / E$ ( 0.1 for diamond) correlated with $\mathrm{CoF}$ are presented (according to Table 1), respectively.

Figure 5. Schematic representation of the $H^{3} / E^{2}$ correlated with $\mathrm{CoF}$ for four types of carbon thin films.

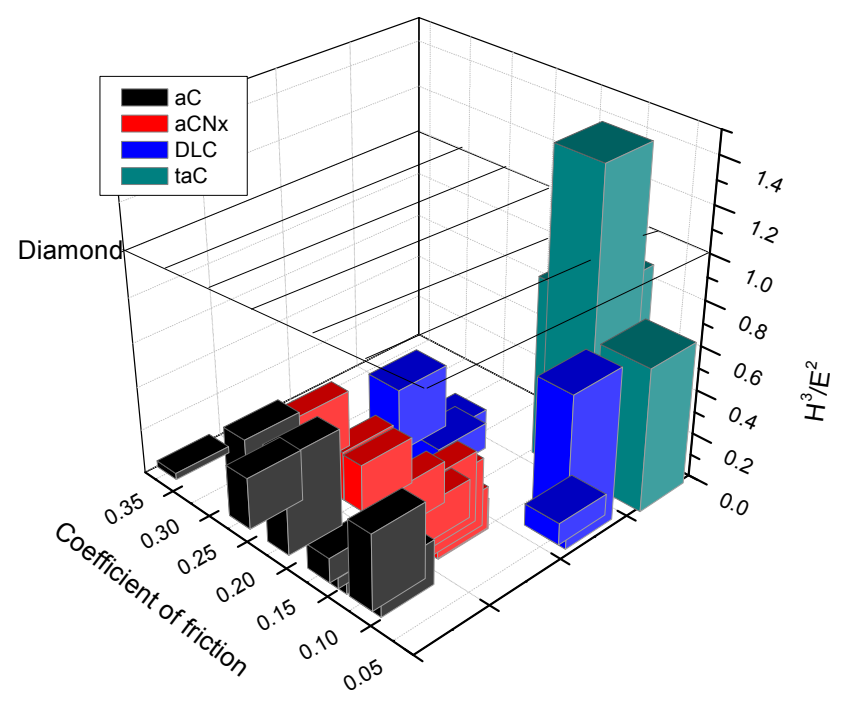

Figure 6. Schematic representation of the $H / E$ correlated with $\mathrm{CoF}$ for four types of carbon thin films. Line is guide to the eye.
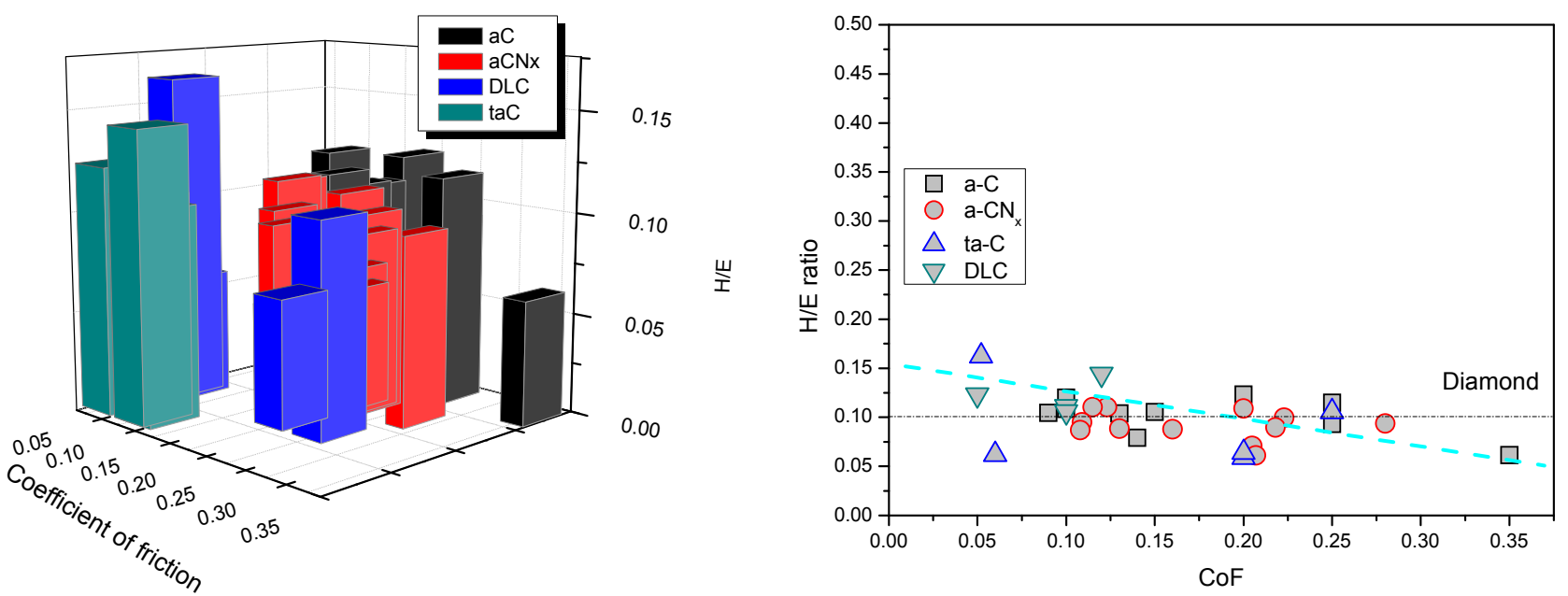

Ranking of materials according to their $H / E$ ratio can provide extremely close agreement to their ranking in terms of wear, as reported in literature [103]. Whilst many researchers have, over the years, confirmed the importance of high $H$ in mitigating wear, the case for a reciprocal relationship between wear resistance and $E$ is less well-proven. Despite the lack of conclusive evidence for a need to enhance elasticity (i.e., to reduce $E$ ) in order to improve wear resistance, the intuitive logic of this route has remained, returning to the $H / E$ ratio as a ranking parameter [103]. The ratio of $H$ to $E$ appears in the so-called "plasticity index", which is widely quoted as a valuable measure in determining the limit of elastic behavior in a surface contact, which is clearly important for the avoidance of wear [103]. The $H / E$ as an indicator of film durability is related to the elastic strain to failure capability (and resilience) 
of a candidate material [104], regarding the need for tribological films to accommodate some degree of substrate deformation.

\subsection{Nanoscale Contact Mechanisms Using Atomistic Simulations}

All factors presented above (see 2.1-2.10), which determine nanotribological behavior of carbon based thin films, have been studied extensively during the last decade using atomistic simulations [105-114]. Atomistic simulations based on MD have immersed as alternative in order to explain friction and transitions between different mechanisms of carbon based films, since analytical models based on continuum mechanics fail to explain friction behavior at the nanoscale. In addition, main computational parts of multiscale tribological calculations for friction and lubricity are based on MD simulations [105].

The definition of the contact edge becomes ambiguous when the atomistic nature of the interface dominates its physical behavior [106-108].

The cohesive energies and chemical reactions of hydrocarbon systems as well as the elastic constants of solid carbon-based materials are accurately described by the Reactive Empirical Bond-Order (REBO) potential [109]. The range of the REBO potential extends as far as the chemical interactions and does not include dispersive forces. The van der Waals interactions are therefore integrated with REBO using an analytical switching function in the regime where the two potentials overlap.

Mylvaganam et al. [110] conducted MD simulations to study the behavior of carbon-diamond, graphite and carbon nanotube-on contact sliding against a diamond asperity vacuum. It was found that, on the nanoscale, graphite and carbon nanotubes exhibit low coefficients of friction, while carbon nanotubes act as a better solid lubricant with a friction coefficient of only about 0.03 in vacuum on the nano/micro scales. The mechanisms of the difference in frictional properties of the three forms of carbon at different dimensional scales were due to the difference in their atomic structures [110]. Gao et al. [27] used MD simulations in order to explore film thickness, counterface termination, and long-range interactions on tribological properties, identifying detailed tribochemical reactions and their effect on friction and wear. The thickness of the amorphous films had no influence on the calculated friction, proving that the structure of the film near the interface is what is dominating the friction. Additionally, the simulation results suggested that the structure of the film, especially the $s p^{3}$-to-s $p^{2}$ ratio, could profoundly affect the tribological properties of the film. Films that contain a larger fraction of surface $s p^{2}$-hybridized carbon will exhibit higher levels of friction than those films with more surface $s p^{3}$-hybridized carbon; this increase in friction is attributed to the increased adhesion from tribochemistry. It should also be noted that changing the $s p^{3}$-to-sp $p^{2}$ ratio within a carbon film will also change its hardness and may also change the film's phonon frequencies. Adhesion, due to the bonding between a carbon on the counterface and a carbon in the film, contributes significantly to the friction. While adhesion between the probe and the film increases the calculated friction; tribochemical reactions within the film lead to a restructuring of the film and a reduction in friction [27]. In addition, there is actually no standard that relates adhesion and friction, which means that range of expected reduction in friction per unit reduction of adhesion is not known [28]. Recently, the first analytical model that can describe the interplay between adhesive forces at the interface and subsurface plastic deformation for single-asperity sliding contacts has been developed by Maneesh Mishra et al. [111]. 
As it is referred by Bhushan et al. [112] adhesion is the main contribution to the friction for nanoscale experiments.

MD simulation studies conducted by Zhang et al. [113] on hydrogenated carbon $\left(\mathrm{CH}_{x}\right)$ films showed the reduction of friction coefficient with surface hydrogenation. These results suggest that pulsed DC magnetron sputtering can produce $\mathrm{CH}_{x}$ films with friction properties similar to those obtained by plasma-enhanced CVD [113].

The hydrogen concentration is crucial for the running-in behavior and the resulting steady-state friction coefficient of a-C: $\mathrm{H}$ tribo-contacts [114]. Similar observations on running-in have been made previously by Gao et al. [27]. Two passivation mechanisms and an explanation of the observed $s p^{3}$ to $s p^{2}$ transformation, which is seen under dry as well as lubricated sliding can be extracted from MD simulations performed by Pastewka et al. [114]. An obvious strategy for reducing friction is to reduce the strength of interatomic interaction between the surfaces, which can be done by surface treatment with the intention of reducing the free surface energies, for example, or by deliberately choosing weakly adhering materials. This is not unlike the macroscopic strategy of lowering friction by selecting metallurgically incompatible materials [28]. MD simulation methods are useful to gain insight for nano-scale interactions and obtain quantitative results for various system models and operating conditions. However, there are still several problems that need to be tackled to obtain simulation results that are closer to the real world [6].

\section{Conclusions}

Due to very unique structures, attractive properties and performance characteristics of carbon based thin films, both the scientific and industrial communities are drawing significant attention to their synthesis, processing and functionalization. Dedicated scientific studies on carbon-based thin films in recent years have led to the development of more exotic versions consisting of unique nanophases and/or structures. Tetrahedral amorphous carbon films are good candidates, among other types of carbon-based films, in terms of the best combination of high $H$ and $E$ values, lower CoF, highly elastic deformation under static nanoindentation testing and nanoscratching up to relatively high normal loads and plastic deformation for high normal loads, however without evidence of film failure. Table 1 summarizes the results of experimental techniques on nanotribological properties of carbon based films.

Connection of the nano-, micro- and macro-scale tribological behavior in terms of experiments (better control and accurate description of the nanoidentation and atomic force microscopy tips) and computational techniques of the tribological interaction of the carbon-based materials remains a challenge. Studies on origin of friction, adhesion, wear and other tribological features at the atomic scale, since they are highly dependent on the surface interactions, using sophisticated experimental and computational tools should be continued in order to provide a deeper understanding of friction in nanoscale. MD simulation methods are useful to gain insight for nano-scale interactions and obtain quantitative results for various system models and operating conditions. However, there are still several problems that need to be tackled to obtain simulation results that are closer to the real world. Table 2 summarizes simulation conditions, used material and results from molecular dynamics techniques applied on carbon based thin film structures in order to study mechanisms of friction and lubricity. 
Table 2. Summary of molecular dynamic simulations of carbon based films nanotribological systems.

\begin{tabular}{|c|c|c|c|}
\hline Year & Simulation condition & Used materials & Results \\
\hline $\begin{array}{c}1999 \\
\text { Cagin et al. }[115]\end{array}$ & Brenner's potential & $\begin{array}{c}\text { Bare diamond } \\
\text { hydrogenated diamond }\end{array}$ & $\begin{array}{l}\text { Dangling bond of surface caused } \\
\text { higher friction force }\end{array}$ \\
\hline $\begin{array}{l}2002 \\
\text { Gao et al. }[27]\end{array}$ & $\begin{array}{l}\text { Brenner's reactive } \\
\text { empirical bond-order } \\
\text { potential (REBO) }\end{array}$ & $\begin{array}{l}\text { Hydrogen-terminated } \\
\text { diamond (111) } \\
\text { counterfaces are in } \\
\text { sliding contact with } \\
\text { diamond (111) surfaces } \\
\text { coated with amorphous, } \\
\text { hydrogen-free } \\
\text { carbon films }\end{array}$ & $\begin{array}{l}\text { Effects of film thickness, adhesion, } \\
\text { and long-range interactions }\end{array}$ \\
\hline $\begin{array}{l}2004 \\
\text { Sulin Zhang et al. [113] }\end{array}$ & Tersoff-Brenner form & $\begin{array}{l}\text { Hydrogenated carbon } \\
\text { films }\left(\mathrm{CH}_{x}\right)\end{array}$ & $\begin{array}{l}\text { Determine how surface hydrogenation } \\
\text { affects friction coefficient }\end{array}$ \\
\hline $\begin{array}{l}2010 \\
\text { Pastewka et al. [114] }\end{array}$ & $\begin{array}{l}\text { Modified Brenner's } \\
\text { reactive empirical } \\
\text { bond-order potential } \\
\text { (REBO) }\end{array}$ & $\begin{array}{l}\text { Diamond-like carbon } \\
\text { (DLC) coatings }\end{array}$ & $\begin{array}{l}\text { Atomistic insights into the running-in, } \\
\text { lubrication, and failure of hydrogenated } \\
\text { diamond-like carbon coatings }\end{array}$ \\
\hline $\begin{array}{l}2010 \\
\text { Mylvaganam et al.[110] }\end{array}$ & $\begin{array}{l}\text { Many-body } \\
\text { Tersoff-Brenner } \\
\text { potential }\end{array}$ & $\begin{array}{l}\text { Carbon-diamond, } \\
\text { graphite and carbon } \\
\text { nanotube }\end{array}$ & $\begin{array}{l}\text { Nanotubes are the best solid lubricant } \\
\text { as it has a low coefficient of friction } \\
\text { that can be maintained across any } \\
\text { dimensional scales from nano to macro } \\
\text { scales due to the large aspect ratio of } \\
\text { length to diameter }\end{array}$ \\
\hline $\begin{array}{l}2012 \\
\text { Bucholz et al.[116] }\end{array}$ & $\begin{array}{l}\text { Brenner's reactive } \\
\text { empirical bond-order } \\
\text { potential (REBO) } \\
\text { coupled with a } \\
\text { Lennard-Jones (LJ) } \\
\text { potential }\end{array}$ & Carbon nano-onions & $\begin{array}{l}\text { The ability of the nano-onions to roll is } \\
\text { inhibited both by increased contact } \\
\text { pressure and the presence of a diamond } \\
\text { core within the nanoparticles that } \\
\text { enhances the formation of interfacial } \\
\text { bonds during friction }\end{array}$ \\
\hline
\end{tabular}

\section{References}

1. Charitidis, C.A. Nanomechanical and nanotribological properties of carbon-based thin films: A review. Int. J. Refract. Metals Hard Mater. 2010, 28, 51.

2. Yoon, E.S.; Singh, R.A.; Oh, H.J.; Kong, H. The effect of contact area on nano/micro-scale friction. Wear 2005, 259, 1424.

3. Lafaye, S.; Gauthier, C.; Schirrer, R. Ploughing friction of a conical tip with blunted spherical extremity: Analytic model with elastic recovery. Tribol. Lett. 2006, 21, 95.

4. Goddard, J.; Wilman, H. A theory of friction and wear during the abrasion of metals. Wear 1962, $5,114$.

5. Müser, M.H. Structural lubricity: Role of dimension and symmetry. Europhys. Lett. 2004, 66, 97.

6. Kim, H.J.; Kim, D.E. Nano-scale Friction: A Review. Int. J. Precis. Eng. Manuf. 2009, 10, 141. 
7. Carpick, R.W.; Salmeron, M. Scratching the surface: Fundamental investigations of tribology with atomic force microscopy. Chem. Rev. 1997, 97, 1163.

8. Urbakh, M.; Klafter, J.; Gourdon, D.; Israelachvili, J. The nonlinear nature of friction. Nature 2004, 430, 525.

9. Bhushan, B.; Israelachvili, J.N.; Landman, U. Nanotribology: Friction, wear and lubrication at the atomic scale. Nature 1995, 374, 607.

10. Hölscher, H.; Schirmeisen, A.; Schwarz, U.D. Principles of atomic friction: from sticking atoms to superlubric sliding. Phil. Trans. R. Soc. A 2008, 336, 1383.

11. Robertson, J. Diamond-like amorphous carbon. Mater. Sci. Eng. R: Rep. 2002, 3, 129.

12. Ferrari, A.C. Tribology of Diamond-Like Carbon Films; Donnet, C., Erdemir, A., Eds.; Springer: New York, NY, USA, 2008; Chapter 2, p. 25.

13. Jacob, W.; Moller, W. On the structure of thin hydrocarbon films. Appl. Phys. 1993, 63, 1771.

14. Grill, A. Diamond-like carbon: State of the art. Diam. Relat. Mater. 1999, 8, 428.

15. Ronkainen, H.; Varjus, S.; Koskinen, J.; Holmberg, K. Differentiating the tribological performance of hydrogenated and hydrogen-free DLC coatings. Wear 2001, 249, 260.

16. Liu, Y.; Erdemir, A.; Meletis, E.I. A study of the wear mechanism of ond-like carbon, films. Surf. Coat. Technol. 1996, 82, 48.

17. Cao, G. Nanostructures and Nanomaterials: Synthesis, Properties and Applications; Imperial College Press: London, UK, 2004; pp. 391-392.

18. Kim, S.H.; Asay, D.B.; Dugger, M.T. Nanotribology and MEMS. Nanotoday 2007, 2, 22.

19. Bhushan, B. Micro/nanotribology and its applications to magnetic storage devices and MEMS. Tribol. Int. 1995, 28, 85.

20. Kim, D.; Cao, D.; Bryant, M.D.; Meng, W.J.; Ling, F.F. Tribological study of microbearings for MEMS applications. Tribology 2005, 127, 537.

21. Achanta, S.; Drees, D.; Celis, J.-P. Friction and nanowear of hard coatings in reciprocating sliding at milli-Newtons loads. Wear 2005, 259, 719.

22. Schonherr, H.; Vancsob, G.J. Molecular resolution imaging and friction anisotropy of highly oriented polyethylene and poly(tetrafluoroethylene) by scanning force microscopy with chemically modified probes. Macromolecules 1997, 30, 6391.

23. Wei, B.; Komvopoulos, K. Nanoscale indentation hardness and wear characterization of hydrogenated carbon thin films. ASME J. Tribol. 1996, 118, 431.

24. Bhushan, B.; Dandavate, C. Thin-film friction and adhesion studies using atomic force microscopy. J. Appl. Phys. 2000, 87, 1201.

25. Deng, H.; Scharf, T.W.; Barnard, J.A. Adhesion assessment of silicon carbide, carbon, and carbon nitride ultrathin overcoats by nanoscratch techniques. J. Appl. Phys. 1997, 81, 5396.

26. Charitidis, C.; Logothetidis, S.; Gioti, M. A comparative study of the nanoscratching behavior of amorphous carbon films grown under various deposition conditions. Surf. Coat. Technol. 2000, $125,201$.

27. Gao, G.T.; Mikulski, P.T.; Harrison, J.A. Molecular-scale tribology of amorphous carbon coatings: Effects of film thickness, adhesion, and long-range interactions. J. Am. Chem. Soc. 2002, 124, 7202-7209.

28. Wong, C.H. Friction at Nanoscale. J. Appl. Mech. Eng. 2012, 1, 1-2. 
29. Gardos, M.N.; Gabelich, S.A. Atmospheric effects of friction, friction noise and wear with silicon and diamond. Part III. SEM tribometry of polycrystalline diamond in vacuum and hydrogen. Tribol. Lett. 1999, 6, 103-112.

30. Grierson, D.S.; Carpick, R.W. Nanotribology of carbon-based materials. Nanotoday 2007, 2, $12-21$.

31. Fontaine, J.; Le Mogne, T.; Loubet, J.L.; Belin, M. Achieving superlow friction with hydrogenated amorphous carbon: Some key requirements. Thin Solid Films 2005, 482, 99-108.

32. Riedo, E.; Chevrier, J.; Comin, F.; Brune, H. Nanotribology of carbon-based thin films: The influence of film structure and surface morphology. Surf. Sci. 2001, 477, 25.

33. Kim, H.G.; Ahn, S.H.; Kim, J.G.; Park, S.J.; Lee, K.R. Effect of Si-incorporation on wear-Corrosion properties of diamond-like carbon films. Thin Solid Films 2005, 482, 299-304.

34. Jiang, Z.; Lu, C.J.; Bogy, D.B.; Bhatia, C.S.; Miyamoto, T. Nanotribological characterization of hydrogenated carbon films by scanning probe microscopy. Thin Solid Films 1995, 258, 75-81.

35. Xuan, S.Z.; Bui, L.; Zeng, X.T.; Li, X. Towards high adherent and tough a-C coatings. Thin Solid Films 2005, 482, 138.

36. Prioli, R.; Jacobsohn, L.G.; Maia da Costa, M.E.H.; Freire, F.L. Nanotribological properties of amorphous carbon-fluorine films. Tribol. Lett. 2003, 15, 177-180.

37. Logothetidis, S.; Charitidis, C.; Patsalas, P. Engineering properties of fully $s p^{3}$ - to $s p^{2}$-bonded carbon films and their modifications after post-growth ion irradiation. Diam. Relat. Mater. 2002, 11, 1095-1099.

38. Lu, W.; Komvopoulos, K.; Patsalas, P.; Charitidis, C.; Gioti, M.; Logothetidis, S. Microstructure and nanomechanical and optical properties of single- and multi-layer carbon films synthesized by radio frequency sputtering. Surf. Coat. Technol. 2003, 168, 12-22.

39. Bruno, P.; Cicala, G.; Losacco, A.M.; Decuzzi, P. Mechanical properties of PECVD hydrogenated amorphous carbon coatings via nanoindentation and nanoscratching techniques. Surf. Coat. Technol. 2004, 180-181, 259-264.

40. Jahanmir, S.; Deckman, D.E.; Ives, L.K.; Feldman, A.; Farrabaugh, E. Tribological characteristics of synthesized diamond films on silicon carbide. Wear 1989, 133, 73-81.

41. Ferrari, A.C.; Robertson, J.; Beghi, M.G.; Bottani, C.E.; Ferulano, R.; Pastorelli, R. Elastic constants of tetrahedral amorphous carbon films by surface Brillouin scattering. Appl. Phys. Lett. 1999, 75, 1893-1895.

42. Bonelli, M.; Ferrari, A.C.; Fioravanti, A.; Li Bassi, A.; Miotello, A.; Ossi, P.M. Structure and mechanical properties of low stress tetrahedral amorphous carbon films prepared by pulsed laser deposition. Eur. Phys. J. B-Condens. Matter Complex Syst. 2002, 25, 269-280.

43. Ouyang, J.H.; Sasaki, S.; Murakami, T. Properties of titanium containing diamond like carbon coatings. Wear 2009, 266, 96-102.

44. Malaczynski, G.W.; Elmoursi, A.A.; Leung, C.H.; Hamdi, A.H.; Campbell, A.B. Improved adhesion of diamondlike coatings using shallow carbon implantation. J. Mater. Res. 2000, 15, 590-592.

45. Lemoine, P.; Zhao, J.F.; Quinn, J.P.; McLaughlin, J.A.; Maguire, P. Hardness measurements at shallow depths on ultra-thin amorphous carbon films deposited onto silicon and $\mathrm{Al}_{2} \mathrm{O}_{3}-\mathrm{TiC}$ substrates. Thin Solid Films 2000, 379, 166-172. 
46. Quinn, J.P.; Lemoine, P.; Maguire, P.; Mc Laughlin, J.A. Ultra-thin tetrahedral amorphous carbon films with strong adhesion, as measured by nanoscratch testing. Diam. Relat. Mater. 2004, 13, 1385-1390.

47. Teo, E.H.T.; Chua, D.H.C.; Tay, B.K. Mechanical properties of alternating high-low $s p^{3}$ content thick non-hydrogenated diamond-like amorphous carbon films. Diam. Relat. Mater. 2007, 16, $1882-1886$.

48. Xu, M.; Cai, X.; Zhao, J.; Chen, Q.; Chu, P.K. Comparative studies on influence of acetylene to argon flow rate ratios on nano-scratch behavior of a-C:H films produced on steel substrates by plasma immersion ion implantation and deposition. Thin Solid Films 2007, 516, 252-256.

49. Huang, L.Y.; Xu, K.W.; Lu, J.; Guelorget, B. Nano-scratching process and fracture mechanism of amorphous carbon films. Wear 2003, 254, 1032-1036.

50. Druza, B.; Yevtukhov, Y.; Novotny, V.; Zaritsky, I.; Kanarov, V.; Polyakov, V.; Rukavishnikov, A. Nitrogenated carbon films deposited using filtered cathodic arc. Diam. Relat. Mater. 2000, 9, 668-674.

51. Ma, X.-G.; Komvopoulos, K.; Wan, D.; Bogy, D.B.; Kim, Y.-S. Effects of film thickness and contact load on nanotribological properties of sputtered amorphous carbon thin films. Wear 2003, 254, 1010-1018.

52. Zhang, T.H.; Huan, Y. Nanoindentation and nanoscratch behaviors of DLC coatings on different steel substrates. Compos. Sci. Technol. 2005, 65, 1409-1413.

53. Bandorf, R.; Paulkowski, D.M.; Schiffmann, K.I.; Küster, R.L.A. Tribological improvement of moving microparts by application of thin films and micropatterning. J. Phys.: Condens. Matter 2008, 20, doi:10.1088/0953-8984/20/35/354018.

54. Bandorf, R.; Luthje, H.; Schiffmann, K.; Staedler, T.; Wortmann, A. Sub-micron coatings with low friction and wear for micro actuators. Microsyst. Technol. 2002, 8, 51-54.

55. Staedler, T.; Schiffmann, K. Correlation of nanomechanical and nanotribological behavior of thin DLC coatings on different substrates. Surf. Sci. 2001, 482, 1125-1129.

56. Maia da Costa, M.E.H.; Sanchez, C.M.T.; Jacobsohn, L.G.; Freire, F.L., Jr. Structural, mechanical, and nanoscale tribological properties of nitrogen-incorporated fluorine-carbon films. Thin Solid Films 2005, 482, 109-114.

57. Corbella, C.; Polo, M.C.; Oncins, G.; Pascual, E.; Andújar, J.L.; Bertran, E. Time-resolved electrical measurements of a pulsed-dc methane discharge used in diamond-like carbon films. Thin Solid Films 2005, 482, 172-176.

58. Wilson, G.M.; Sullivan, J.L. An investigation into the effect of film thickness on nanowear with amorphous carbon-based coatings. Wear 2009, 266, 1039-1043.

59. Bolelli, G.; Lusvarghi, L.; Mantini, F.P.; Pitacco, F.; Volz, H. Enhanced tribological properties of PECVD DLC coated thermally sprayed coatings. Surf. Coat. Technol. 2008, 202, 4382-4386.

60. Crombez, R.; Mc Minis, J.; Veerasamy, V.S.; Shen, W. Experimental study of mechanical properties and scratch resistance of ultra-thin diamond-like-carbon (DLC) coatings deposited on glass. Tribol. Int. 2011, 44, 55-62. 
61. Tsotsos, C.; Polychronopoulou, K.; Demas, N.G.; Constantinides, G.; Gravani, S.; Böbel, K.; Baker, M.A.; Polycarpou, A.A.; Rebholz, C. Mechanical and high pressure tribological properties of nanocrystalline $\mathrm{Ti}(\mathrm{N}, \mathrm{C})$ and amorphous $\mathrm{C}: \mathrm{H}$ nanocomposite coatings. Diam. Relat. Mater. 2010, 19, 960-963.

62. Zheng, X.H.; Tu, J.P.; Song, R.G. Microstructure and tribological performance of $\mathrm{CN}_{x}-\mathrm{TiN}_{x}$ composite films prepared by pulsed laser deposition. Mater. Design 2010, 31, 1716-1719.

63. Buijnsters, J.G.; Camero, M.; Vázquez, L.; Agulló-Rueda, F.; Gago, R.; Jiménez, I.; Gómez-Aleixandre, C.; Albella, J.M. Tribological study of hydrogenated amorphous carbon films with tailored microstructure and composition produced by bias-enhanced plasma chemical vapour deposition. Diam. Relat. Mater. 2010, 19, 1093-1102.

64. Zheng, X.H.; Tu, J.P.; Song, R.G. Fabrication, microstructure and tribological behavior of pulsed laser deposited a-CN $\mathrm{CN}_{x}$ TiN multilayer films. Surf. Coat. Technol. 2010, 205, 902-908.

65. Liu, D.G.; Tu, J.P.; Hong, C.F.; Gu, C.D.; Mai, Y.J.; Chen, R. Improving mechanical properties of a-CN ${ }_{x}$ films by Ti-TiN/CN $x$ gradient multilayer. App. Surf. Sci. 2010, 257, 487-494.

66. Borrero-Lopez, O.J.; Hoffman, M.J.; Bendavid, A.; Martin, P.J. Substrate effects on the mechanical properties and contact damage of diamond-like carbon thin films. Diam. Relat. Mater. 2010, 19, 1273-1280.

67. Gao, G.; Cannara, R.J.; Carpick, R.W.; Harrison, J.A. Atomic-scale friction on diamond: A comparison of different sliding directions on (001) and (111) surfaces using MD and AFM. Langmuir 2007, 23, 5394-5405.

68. Charitidis, C.; Logothetidis, S. Effects of normal load on nanotribological properties of sputtered carbon nitride films. Diam. Relat. Mater. 2005, 14, 98.

69. Enomoto, Y.; Tabor, D. The frictional anisotropy of diamond. Proc. R. Soc. Lond. A 1981, 373, 405.

70. Germann, G.J.; Cohen, S.R.; Neubauer, G.; McClelland, G.M.; Seki, H. Atomic scale friction of a diamond tip on diamond (100) and (111) surfaces. Appl. Phys. 1993, 73, 163.

71. Gogotsi, Y.G.; Kailer, A.; Nickel, K.G. Pressure-induced phase transformations in diamond. J. Appl. Phys. 1998, 84, 1299-1304.

72. Lee, E.H.; Hembree, D.M., Jr.; Rao, G.R.; Mansur, L.K. Raman scattering from ion-implanted diamond, graphite, and polymers. Phys. Rev. B 1993, 48, 15540-15551.

73. Erdemir, A.; Halter, M.; Fenske, G.R.; Zuiker, C.; Csencsits, R.; Krauss, A.R.; Gruen, D.M. Friction and wear mechanisms of smooth diamond films during sliding in air and dry nitrogen, Tribol. Trans. 1997, 40, 667-673.

74. Carpinteri, A.; Paggi, M. Size-scale effects on the friction coefficient. Int. J. Solids Struct. 2005, 42, 2901-2910.

75. Tomala, A.; Roy, M.; Franek, F. Nanotribology of Mo-Se-C films. Philos. Mag. 2010, 90, 3827-3843.

76. Hayward, I.P.; Singer, I.L.; Seitzman, L.E. The effect of roughness on the friction of diamond on CVD diamond coatings. Wear 1991, 157, 215.

77. Bull, S.J.; Chalkar, P.R.; Johnston, C.; Moore, V. The effect of roughness on the friction and wear of diamond thin film. Surf. Coat. Technol. 1994, 68, 603-610. 
78. Schneider, A.; Steinmueller-Nethl, D.; Roy, M.; Franek, F. Enhanced tribological performances of nanocrystalline diamond film. Int. J. Refract. Metals Hard Mater. 2010, 28, 40-50.

79. Enachescu, M.; Van Den Oetelaar, R.J.A.; Carpick, R.W.; Ogletree, D.F.; Flipse, C.F.J.; Salmeron, M. Atomic force microscopy study of an ideally hard contact: The diamond (111)/tungsten carbide interface. Phys. Rev. Lett. 1998, 81, 1877-1880.

80. Medyanik, S.N.; Liu, W.K.; Sung, I.H.; Carpick, R.W. Predictions and observations of multiple slip modes in atomic-scale friction. Phys. Rev. Lett. 2006, 97, 1361061-4.

81. Socoliuc, A.; Bennewitz, R.; Gnecco, E.; Meyer, E. Transition from stick-slip to continuous sliding in atomic friction: Entering a new regime of ultralow friction. Phys. Rev. Lett. 2004, 92, doi:10.1103/PhysRevLett.97.136106.

82. Krylov, S.Y.; Dijksman, J.A.; Van Loo, W.A.; Frenken, J.W.M. Stick-slip motion in spite of a slippery contact: Do we get what we see in atomic friction? Phys. Rev. Lett. 2006, 97, doi:10.1103/PhysRevLett.97.166103.

83. Erdemir, A.; Eryilmaz, O.L.; Fenske, G. Synthesis of diamondlike carbon films with superlow friction and wear properties. J. Vac. Sci. Technol. A: Vac. Surf. Films 2000, 18, 1987-1992.

84. Donnet, C.; Belin, M.; Auge, J.C.; Martin, J.M.; Grill, A.; Patel, V. Tribochemistry of diamond-like carbon coatings in various environments. Surf. Coat. Technol. 1994, 68, 626-631.

85. Erdemir, A. The role of hydrogen in tribological properties of diamond-like carbon films. Surf. Coat. Technol. 2001, 146, 292-297.

86. Donnet, C.; Mogne, T.L.; Ponsonnet, L.; Belin, M.; Grill, A.; Patel, V.; Jahnes, C. The respective role of oxygen and water vapor on the tribology of hydrogenated diamond-like carbon coatings. Tribol. Lett. 1998, 4, 259-265.

87. Erdemir, A. Superlubricity and wearless sliding in diamond-like carbon films. Mater. Res. Soc. Symp. Proc. 2002, 697, 391-403.

88. Erdemir, A.; Eryilmaz, O.L.; Nilufer, I.B.; Fenske, G.R. Synthesis of superlow-friction carbon films from highly hydrogenated methane plasmas. Surf. Coat. Technol. 2000, 133, 448-454.

89. Erdemir, A.; Nilufer, I.B.; Eryilmaz, O.L.; Beschliesser, M.; Fenske, G.R. Friction and wear performance of diamond-like carbon films grown in various source gas plasmas. Surf. Coat. Technol. 1999, 120, 589-593.

90. Erdemir, A.; Eryilmaz, O.L.; Nilufer, I.B.; Fenske, G.R. Effect of source gas chemistry on tribological performance of diamond-like carbon films. Diam. Relat. Mater. 2000, 9, 632-637.

91. Donnet, C.; Grill, A. Friction control of diamond-like carbon coatings. Surf. Coat. Technol. 1997, 94, 456-462.

92. Donnet, C.; Fontaine, J.; Grill, A.; Le Mogne, T. The role of hydrogen on the friction mechanism of diamond-like carbon films. Tribol. Lett. 2001, 9, 137-142.

93. Fontaine, J.; Belin, M.; Le Mogne, T.; Grill, A. How to restore superlow friction of DLC: The healing effect of hydrogen gas. Tribol. Int. 2004, 37, 869-877.

94. Erdemir, A.; Donnet, C. Tribology of diamond-like carbon films: Recent progress and future prospects. J. Phys. D: Appl. Phys. 2006, 39, R311.

95. Uchidate, M.; Liu, H.; Iwabuchi, A.; Yamamoto, K. Effects of water environment on tribological properties of DLC rubbed against brass. Wear 2009, 267, 1589-1594. 
96. Sundararajan, S.; Bhushan, B. Micro/Nanotribology of ultra-thin hard amorphous carbon coatings using atomic force/friction force microscopy. Wear 1999, 225, 678-689.

97. Lu, W.; Komvopoulos, K. Nanomechanical and nanotribological properties of carbon, chromium, and titanium carbide ultrathin films. J. Tribol. 2001, 123, 717-724.

98. Beake, B.D.; Lau, S.P. Nanotribological and nanomechanical properties of 5-80 nm tetrahedral amorphous carbon films on silicon. Diam. Relat. Mater. 2005, 14, 1535-1542.

99. Jiang, Z.; Lu, C.J.; Bogy, D.B.; Bhatia, C.S.; Miyamoto, T. Nanotribological evaluations of hydrogenated carbon films as thin as $5 \mathrm{~nm}$ on magnetic rigid disks. IEEE Trans. Magn. 1995, 31, 3015-3017.

100. Singh, R.K.; Xie, Z.H.; Bendavid, A.; Martin, P.J.; Munroe, P.; Hoffman, M. Effect of substrate roughness on the contact damage of DLC coatings. Diam. Relat. Mater. 2008, 17, 975-979.

101. Johnson, K.L. Contact Mechanics; Cambridge University Press: Cambridge, UK, 1985; p. 155.

102. Charitidis, C.; Logothetidis, S.; Douka, P. Nanoindentation and nanoscratching studies of amorphous carbon films. Diam. Relat. Mater. 1999, 8, 558-562.

103. Leyland, A.; Matthews, A. On the significance of the $H / E$ ratio in wear control: A nanocomposite film approach to optimised tribological behavior. Wear 2000, 246, 1.

104. Leyland, A.; Matthews, A. Design criteria for wear-resistant nanostructured and glassy-metal coatings. Surf. Coat. Technol. 2004, 177, 317-324.

105. Sham, T.-L.; Tichy, J. A scheme for hybrid molecular dynamics/finite element analysis of thin film lubrication. Wear 1997, 207, 100-106.

106. Mo, Y.; Turner, K.T.; Szlufarska, I. Friction laws at the nanoscale. Nature 2009, 457, $1116-1119$

107. Johnson, K.L. Adhesion and friction between a smooth elastic spherical asperity and a plane surface. Proc. R. Soc. Lond. Ser. A 1997, 453, 163-179.

108. Luan, B.; Robbins, M.O. Contact of single asperities with varying adhesion: Comparing continuum mechanics to atomistic simulations. Phys. Rev. E 2006, 74, doi:10.1103/PhysRevE. 74.026111.

109. Brenner, D.W.; Shenderova, O.A.; Harrison, J.A.; Stuart, S.J.; Ni, B.; Sinnott, S.B. A second-generation reactive empirical bond order (REBO) potential energy expression for hydrocarbons. J. Phys. Condens. Matter 2002, 14, 783.

110. Mylvaganam, K.; Zhang, L.C. Nano-Friction of some carbon allotropes. J. Comput. Theor. Nanosci. 2010, 7, 2199-2202.

111. Mishra, M.; Egberts, P.; Bennewitz, R.; Szlufarska, I. Friction model for single-asperity elastic-plastic contacts. Phys. Rev. B 2012, 86, doi:10.1103/PhysRevB.86.045452.

112. Bhushan, B. Nanotribology, nanomechanics and nanomaterials characterization. Philos. Trans. R. Soc. A: Math. Phys. Eng. Sci. 2008, 366, 1351-1381.

113. Zhang, S.; Wagner, G.; Medyanik, S.N.; Liu, W.K.; Yu, Y.H.; Chung, Y.W. Experimental and molecular dynamics simulation studies of friction behavior of hydrogenated carbon films. Surf. Coat. Technol. 2004, 177, 818-823.

114. Pastewka, L.; Moser, S.; Moseler, M. Atomistic insights into the running-in, lubrication, and failure of hydrogenated diamond-like carbon coatings. Tribol. Lett. 2010, 39, 49-61. 
115. Çagin, T.; Che, J.; Gardos, M.N.; Fijany, A.; Goddard, W.A., III. Simulation and experiments on friction and wear of diamond: A material for MEMS and NEMS application. Nanotechnology 1999, 10, 278.

116. Bucholz, E.W.; Phillpot, S.R.; Sinnott, S.B. Molecular dynamics investigation of the lubrication mechanism of carbon nano-onions. Comput. Mater. Sci. 2012, 54, 91-96.

(C) 2013 by the authors; licensee MDPI, Basel, Switzerland. This article is an open access article distributed under the terms and conditions of the Creative Commons Attribution license (http://creativecommons.org/licenses/by/3.0/). 